\title{
RISCOS À SAÚDE E ADOECIMENTO DO AGRICULTOR DECORRENTES DAS ATIVIDADES RURAIS: REVISÃO INTEGRATIVA DE LITERATURA
}

\author{
RISKS TO HEALTH AND FARMER'S DISEASE ARISING FROM \\ RURAL ACTIVITIES: INTEGRATIVE LITERATURE REVIEW
}

Luana Vieira Coelho Ferreira ${ }^{1}$

Rivanildo Dallacort ${ }^{2}$

William Fenner ${ }^{3}$

Raimundo Nonato Cunha de França ${ }^{4}$

Ana Carolina Macri Gaspar Vendramini ${ }^{5}$

RESUMO: Objetivou-se analisar as evidências científicas sobre os riscos à saúde e doenças que acometem os agricultores decorrentes das atividades rurais. Trata-se de uma revisão integrativa de literatura realizada na base de dados eletrônicas SciELO e na Biblioteca Virtual em Saúde (BVS) com os seguintes descritores: agricultores, trabalhadores rurais, população rural, exposição ocupacional, exposição ambiental, riscos ocupacionais, doenças dos trabalhadores agrícolas, doenças profissionais e estresse psicológico. Foram incluídos textos completos, do período entre 2010-2020, nos idiomas inglês, português e espanhol. A revisão foi realizada em seis etapas. Foram encontrados 104 artigos, após leitura do título, resumo e palavras-chave 89 artigos foram excluídos, resultando em uma amostra de 15 artigos para análise final. Os resultados foram descritos em cinco categorias temáticas, sendo: riscos à saúde decorrentes do uso e exposição aos agrotóxicos, implicações à saúde decorrentes da fumicultura, implicações na saúde mental decorrentes do trabalho rural, riscos à saúde decorrentes da atividade extrativista e adoecimento do agricultor decorrentes a diferentes exposições no trabalho rural. Os

\footnotetext{
1 Enfermeira. Mestre em Ambiente e Sistemas de Produção Agrícola. Programa de Pós-Graduação Interdisciplinar em Ambiente e Sistemas de Produção Agrícola (PPGASP) da Universidade do Estado de Mato Grosso (UNEMAT).

2 Doutor em Agronomia. Docente. Programa de Pós-Graduação Interdisciplinar em Ambiente e Sistemas de Produção Agrícola (PPGASP) da Universidade do Estado de Mato Grosso (UNEMAT).

${ }^{3}$ Doutor em Agricultura Tropical. Pós Doutorando. Programa de Pós-Graduação Interdisciplinar em Ambiente e Sistemas de Produção Agrícola (PPGASP) da Universidade do Estado de Mato Grosso (UNEMAT).

${ }^{4}$ Doutor em Ciências Sociais. Docente. Programa de Pós-Graduação Interdisciplinar em Ambiente e Sistemas de Produção Agrícola (PPGASP) da Universidade do Estado de Mato Grosso (UNEMAT).

${ }^{5}$ Doutora em Enfermagem. Docente. Universidade do Estado de Mato Grosso (UNEMAT).
} 
agricultores estão expostos à vários riscos à saúde, decorrentes de diferentes atividades agrícolas, entre eles, os riscos físicos, químicos, biológicos, ergonômicos, organizacionais e à saúde mental. Muitos riscos são minimizados com a utilização de Equipamentos de Proteção Individual, no entanto, é necessário maior sensibilização sobre a importância do uso correto desses equipamentos na prevenção dos agravos.

Palavras chave: Agricultores; Trabalhadores Rurais; Exposição Ocupacional; Exposição Ambiental; Doenças Profissionais.

ABSTRACT: This study goals to analyze the scientific evidence on health risks and diseases that affect farmers resulting from rural activities. It is an integrative literature review carried out in the electronic database SciELO and in the Virtual Health Library (VHL), with the following descriptors: farmers, rural workers, rural population, exhibition occupational, environmental exposure, occupational risks, diseases of agricultural workers, occupational diseases and psychological stress. Full texts, from the period 2010-2020, in English, Portuguese and Spanish were included. The review was carried out in six stages. 104 articles were found, after reading the title, abstract and keywords 89 articles were excluded, resulting in a sample of 15 articles for final analysis. The results were described in five thematic categories, namely: health risks resulting from the use and exposure to pesticides, health implications from tobacco farming, mental health implications from rural work, health risks from extractive activities and illness from the farmer resulting from to different exposures in rural work. Farmers are exposed to various health risks arising from different agricultural activities, including physical, chemical, biological, ergonomic, organizational and mental health risks. Many risks are minimized with the use of Personal Protective Equipment, however, there is a need for greater awareness of the importance of the correct use of this equipment in preventing injuries.

Keywords: Farmers; Rural Workers; Occupational Exposure; Environmental Exposure; Professional Diseases. 


\section{INTRODUÇÃO}

A agricultura é uma atividade essencial no mundo todo, responsável por suprir as necessidades da humanidade no que se refere a alimentação e outras matériasprimas, por isso, enfrenta um grande desafio, atender as demandas crescentes da sociedade utilizando de forma consciente os recursos naturais (LOPES; CONTINI, 2012). No Brasil, a agricultura se destaca por estar entre as maiores do mundo, importando e exportando alimentos e matéria prima (DELGADO; BERGAMASCO, 2017).

Já a atividade rural pode ser definida como "a exploração agropecuária e extrativista vegetal e animal, bem como os serviços afins prestados pelo produtor, de acordo com as disposições legais em vigor" (BRASIL, 2012). Conforme Dias (2006, p. 4) "[...] a atividade rural no Brasil inclui a lavoura, pecuária, florestal, extrativismo e a pesca artesanal".

Neste contexto, temos a importância do agricultor, também conhecido como trabalhador/empregado rural ou rurícola, presente desde os primórdios da humanidade desenvolvendo atividades agrícolas e/ou pecuárias e semelhantes, consideradas essenciais para o cenário socioeconômico (SILVA, 2014). Os agricultores familiares, trabalhadores rurais, camponeses, comunidades tradicionais (ribeirinhas, quilombolas...) estão entre as populações do campo e da floresta, que tem na relação com a terra o modo de vida, produção e reprodução social (BRASIL, 2013).

Embora a agricultura atenda uma das necessidades básicas dos seres humanos por meio da produção de alimentos, ela pode trazer consigo vários impactos para o ambiente e saúde, como o desmatamento, diminuição da biodiversidade, uso intensivo do solo, assoreamento e erosão do solo, degradação das águas, uso de agrotóxicos de maneira inadequada, fatores estes que afetam diretamente a dinâmica ambiental e a saúde humana (DEUS; BAKONYI, 2012). 
Conforme Fenzke e colaboradores (2018, p. 222) "[...] dependendo dos fatores de risco aos quais os trabalhadores estão expostos, serão desenvolvidos tipos específicos de doenças que podem ser manifestadas em curto ou longo prazo". Por isso, a saúde das populações do campo e da floresta são determinadas por diferentes condições (ambientais, sociais, econômicas, políticas e culturais), estes determinantes estão associados as maneiras dos indivíduos adoecer e morrer, sendo necessária a compreensão desses fatores, para que sejam realizadas ações intersetoriais no intuito de melhorar o nível de qualidade de vida e saúde deste público (BRASIL, 2013).

Sendo a agricultura a principal base econômica do Brasil, torna-se primordial o amparo e cuidado aos agricultores, avaliando se as condições de trabalho são adequadas (POSSAMAI; BEZERRA, 2018). É preciso um cuidado (físico e mental) voltado a esses trabalhadores, contemplando a avaliação, monitoramento e assistência necessária, no sentido de amenizar os riscos à saúde (LEITE et al., 2021). O que justifica a importância científica e social de estudos que abordem os fatores de risco à saúde e de adoecimento dos agricultores. Diante ao exposto, este estudo tem como objetivo analisar as evidências científicas sobre os riscos à saúde e doenças que acometem o agricultor decorrentes do trabalho rural.

\section{MATERIAIS E MÉTODOS}

A pesquisa foi realizada por meio de uma revisão integrativa de literatura norteada pela seguinte pergunta "O que há disponível na literatura sobre os riscos à saúde e doenças que acometem o agricultor decorrentes do trabalho rural?". A revisão integrativa caracteriza-se por ser uma síntese dos estudos relevantes em uma determinada temática, facilitando o saber crítico, a incorporação de evidências científicas e a fundamentação para tomadas de decisão pelos profissionais de saúde em diferentes áreas de atuação (MENDES; SILVEIRA; GALVÃO, 2008).

Para a construção desta pesquisa seguiram-se as seis etapas da revisão integrativa descritas por Mendes, Silveira e Galvão (2008), sendo: identificação do 
tema, seleção da hipótese ou questão de pesquisa, determinação dos objetivos e palavras-chave; estabelecimento dos critérios para inclusão e exclusão de estudos, uso das bases de dados e seleção dos estudos; extração, organização e sumarização das informações, construção de banco de dados e categorização dos estudos; avaliação dos estudos incluídos na revisão; interpretação dos resultados e por fim, a apresentação da revisão/síntese do conhecimento.

O desenvolvimento da pesquisa foi realizado no período entre junho a julho de 2020. Os Descritores em Ciências da Saúde (DeCS) utilizados foram: Agricultores, Trabalhadores Rurais, População Rural; Exposição Ocupacional, Exposição Ambiental, Riscos Ocupacionais; Doenças dos Trabalhadores Agrícolas, Doenças Profissionais, Estresse Psicológico. Para ampliar a sensibilidade da busca utilizou-se o operador booleano $O R$ entre as palavras sinônimos e o operador $A N D$ entre as categorias população, exposição e desfecho.

As buscas foram realizadas na base de dados eletrônica Scientific Electronic Library Online (SciELO) e Biblioteca Virtual em Saúde (BVS) indexada nas bases Literatura Latino-Americana e do Caribe em Ciências e Saúde (LILACS), Medical Literature Analysis and Retrieval System Online (MEDLINE), Banco de dados Bibliográficos Especializado na Área de Enfermagem do Brasil (BDENF) e Índice Bibliográfico Español en Ciencias de la Salud (IBECS).

Para a seleção dos artigos foram utilizados como critérios de inclusão: textos completos, dos últimos dez anos (2010-2020), nos idiomas inglês, português e espanhol. Com os filtros encontrou-se 104 estudos (97 BVS e 7 SciELO), destes, após a leitura do título, resumo e palavras-chave, foram excluídos 89 publicações devido a um ou mais enquadramento nos seguintes critérios de exclusão: artigos de revisão de literatura (3), reflexão teórica (1), dissertações (3), teses (2), manuais e coletâneas (1), estudos em que os sujeitos da pesquisa eram crianças e adolescentes (10), artigos repetidos (13), que não contemplavam o objetivo e/ou problema de pesquisa proposto (52) e que não estavam disponíveis on-line, com acesso livre (2) e de forma gratuita (2). Ao todo, foram selecionadas 15 publicações, submetidas à análise.

Os artigos selecionados na revisão foram organizados, com a apresentação das características dos estudos: identificação, título, autor(es), revista, ano de 
publicação, tipo de estudo, base de dados e objetivos (Quadro 1). Posteriormente, foram agrupados em categorias, de acordo com as similaridades do conhecimento e aspectos que a temática vem sendo analisada e estudada (VOSGERAU; ROMANOVSKI, 2014).

Quadro 1 - Caracterização dos artigos selecionados para revisão:

\begin{tabular}{|c|c|c|c|c|}
\hline $\begin{array}{c}\text { Identificação e Título } \\
\text { do Estudo }\end{array}$ & $\begin{array}{c}\text { Autor(es) / } \\
\text { Revista / Ano }\end{array}$ & $\begin{array}{c}\text { Tipo e Local de } \\
\text { Estudo }\end{array}$ & $\begin{array}{l}\text { Base de } \\
\text { dados }\end{array}$ & Objetivo(s) \\
\hline $\begin{array}{lr}\text { A1 - Uso de } & \text { de } \\
\text { agrotóxicos } & \text { na } \\
\text { produção de soja do } \\
\text { Estado do } & \text { Mato } \\
\text { Grosso: um estudo } \\
\text { preliminar de riscos } \\
\text { ocupacionais } & \text { e } \\
\text { ambientais. } & \end{array}$ & $\begin{array}{l}\text { Belo et al. / } \\
\text { Rev. bras. } \\
\text { Saúde ocup. / } \\
2012 .\end{array}$ & $\begin{array}{c}\text { Estudo } \\
\text { exploratório } \\
\text { descritivo / } \\
\text { Mato Grosso, } \\
\text { Brasil. }\end{array}$ & $\begin{array}{l}\text { bvs - } \\
\text { LILACS. }\end{array}$ & $\begin{array}{l}\text { Identificar e discutir } \\
\text { alguns dos principais } \\
\text { riscos associados ao uso } \\
\text { de agrotóxicos na na } \\
\text { produção de soja do } \\
\text { estado de Mato Grosso, } \\
\text { evidenciando, } \\
\text { principalmente, acional e } \\
\text { dimensões ocupacion } \\
\text { ambiental. }\end{array}$ \\
\hline $\begin{array}{l}\text { A2- Skin cancer in } \\
\text { rural workers: } \\
\text { nursing knowledge } \\
\text { and intervention. }\end{array}$ & $\begin{array}{l}\text { Cezar-Vaz et } \\
\text { al. / Rev Esc } \\
\text { Enferm USP / } \\
2015 .\end{array}$ & $\begin{array}{c}\text { Estudo } \\
\text { observacional- } \\
\text { exploratório. / } \\
\text { Rio Grande do } \\
\text { Sul, Brasil. }\end{array}$ & $\begin{array}{l}\text { bvs - } \\
\text { LILACS. }\end{array}$ & $\begin{array}{l}\text { Identificar a exposição de } \\
\text { trabalhadores rurais à } \\
\text { radiação solar ultravioleta } \\
\text { e aos pesticidas; } \\
\text { identificar casos } \\
\text { pregressos de câncer de } \\
\text { pele e aplicar a ação } \\
\text { clínica e comunicativa de } \\
\text { Enfermagem aos } \\
\text { trabalhadores rurais com } \\
\text { diagnóstico pregresso de } \\
\text { câncer de pele. }\end{array}$ \\
\hline $\begin{array}{l}\text { A3 - Prevalência e } \\
\text { fatores associados } \\
\text { ao tabagismo em } \\
\text { fumicultores do Sul } \\
\text { do Brasil. }\end{array}$ & $\begin{array}{l}\text { Fiori et al. } \\
\text { /Cad. Saúde } \\
\text { Pública. / } \\
2016 .\end{array}$ & $\begin{array}{c}\text { Estudo } \\
\text { transversal de } \\
\text { base } \\
\text { populacional. / } \\
\text { Rio Grande do } \\
\text { Sul, Brasil. } \\
\end{array}$ & $\begin{array}{l}\text { bvs - } \\
\text { LILACS. }\end{array}$ & $\begin{array}{l}\text { Descrever a prevalência } \\
\text { de tabagismo e fatores } \\
\text { associados } \\
\text { fumicultores. }\end{array}$ \\
\hline $\begin{array}{l}\text { A4 - Suinocultor: } \\
\text { vivências de prazer e } \\
\text { sofrimento no } \\
\text { trabalho precário. }\end{array}$ & $\begin{array}{l}\text { Giongo, } \\
\text { Monteiro e } \\
\text { Sobrosa. / } \\
\text { Psicologia \& } \\
\text { Sociedade / } \\
2017 .\end{array}$ & $\begin{array}{l}\text { Estudo } \\
\text { delineamento } \\
\text { qualitativo. / } \\
\text { Não apresenta } \\
\text { o local de } \\
\text { estudo. }\end{array}$ & $\begin{array}{l}\text { bvs - } \\
\text { LILACS. }\end{array}$ & $\begin{array}{l}\text { Analisar as vivências de } \\
\text { prazer e de sofrimento no } \\
\text { trabalho de suinocultores, } \\
\text { além de caracterizar a } \\
\text { organização do trabalho e } \\
\text { de compreender as } \\
\text { estratégias defensivas } \\
\text { utilizadas. }\end{array}$ \\
\hline $\begin{array}{lr}\text { A5 - } & \text { Agriculture } \\
\text { related } & \text { corneal } \\
\text { injuries. } & \end{array}$ & $\begin{array}{l}\text { Goel et al. / } \\
\text { Nepal J } \\
\text { Ophthalmol. / } \\
2013 .\end{array}$ & $\begin{array}{l}\text { Estudo } \\
\text { quantitativo. / } \\
\text { Índia. }\end{array}$ & $\begin{array}{l}\text { bvs - } \\
\text { MEDLINE. }\end{array}$ & $\begin{array}{l}\text { Estudar a prevalência e o } \\
\text { modo de lesões } \\
\text { corneanas relacionadas à } \\
\text { agricultura na aldeia de } \\
\text { Badkali, MuzaffarNagar, } \\
\text { Western Uttar Pradesh, } \\
\text { Índia, entre } 2005 \text { e 2006. }\end{array}$ \\
\hline
\end{tabular}




\begin{tabular}{|c|c|c|c|c|}
\hline $\begin{array}{l}\text { A6 - Percepção de } \\
\text { riscos do uso de } \\
\text { agrotóxicos por } \\
\text { trabalhadores da } \\
\text { agricultura familiar } \\
\text { do município de Rio } \\
\text { Branco, AC. }\end{array}$ & $\begin{array}{l}\text { Gregolis, } \\
\text { Pinto e Peres. } \\
\text { / Rev. bras. } \\
\text { Saúde ocup. / } \\
2012 .\end{array}$ & $\begin{array}{l}\text { Estudo de } \\
\text { percepção de } \\
\text { riscos } \\
\text { relacionados } \\
\text { ao trabalho } \\
\text { rural. / Acre, } \\
\text { Brasil. }\end{array}$ & $\begin{array}{l}\text { bvs - } \\
\text { LILACS. }\end{array}$ & $\begin{array}{lcc}\text { Conhecer as percepções } \\
\text { de risco associadas ao } \\
\text { uso de agrotóxicos no } \\
\text { trabalho } & \text { rural } & \text { de } \\
\text { pequenos } & \text { produtores } \\
\text { rurais. } & & \end{array}$ \\
\hline $\begin{array}{l}\text { A7 - Farmers' Cohort } \\
\text { for Agricultural } \\
\text { Work-Related } \\
\text { Musculoskeletal } \\
\text { Disorders (FARM) } \\
\text { Study: Study Design, } \\
\text { Methods, and } \\
\text { Baseline } \\
\text { Characteristics of } \\
\text { Enrolled Subjects. }\end{array}$ & $\begin{array}{l}\text { Jo et al. / J } \\
\text { Epidemiol. } \\
\text { /2016. }\end{array}$ & $\begin{array}{l}\text { Estudo de } \\
\text { coorte. / Coréia } \\
\text { do Sul. }\end{array}$ & $\begin{array}{c}\text { bvs - } \\
\text { MEDLINE. }\end{array}$ & $\begin{array}{lr}\text { O estudo de } & \text { coorte de } \\
\text { agricultores } & \text { em } \\
\text { andamento } & \text { sobre } \\
\text { distúrbios } & \\
\text { osteomusculares } & \\
\text { relacionados ao } & \\
\text { agrícola foi desenvolho } \\
\text { para avaliar o estado de } \\
\text { saúde e er fatores } \\
\text { relacionados } \\
\text { agricultores. }\end{array}$ \\
\hline $\begin{array}{l}\text { A8 - Identification of } \\
\text { barriers to the } \\
\text { prevention of and } \\
\text { treatment of heat- } \\
\text { related illness } \\
\text { farmworkers using } \\
\text { activity-oriented, } \\
\text { participatory rural } \\
\text { appraisal focus } \\
\text { group methods. }\end{array}$ & $\begin{array}{c}\text { Lam et al. / } \\
\text { BMC Public } \\
\text { Health / } 2013 .\end{array}$ & $\begin{array}{l}\text { Estudo de } \\
\text { abordagem } \\
\text { qualitativa. } \\
\text { Washington, } \\
\text { EUA. }\end{array}$ & $\begin{array}{c}\text { bvs - } \\
\text { MEDLINE. }\end{array}$ & $\begin{array}{l}\text { A doença relacionada ao } \\
\text { calor é uma causa } \\
\text { importante de doença não } \\
\text { fatal e morte em } \\
\text { trabalhadores } \\
\text { rurais. Procuramos } \\
\text { identificar possíveis } \\
\text { barreiras à prevenção e } \\
\text { tratamento desta doença } \\
\text { em trabalhadores latinos. }\end{array}$ \\
\hline $\begin{array}{l}\text { A9 - Transtornos } \\
\text { mentais comuns em } \\
\text { agricultores, relação } \\
\text { com agrotóxicos, } \\
\text { sintomas físicos e } \\
\text { doenças } \\
\text { preexistentes. }\end{array}$ & $\begin{array}{c}\text { Morim e } \\
\text { Stumm. / } \\
\text { Psico / } 2018 .\end{array}$ & $\begin{array}{l}\text { Estudo } \\
\text { transversal, } \\
\text { descritivo e } \\
\text { analítico. / Rio } \\
\text { Grande do Sul, } \\
\text { Brasil. }\end{array}$ & $\begin{array}{c}\text { bvs - } \\
\text { LILACS. }\end{array}$ & $\begin{array}{l}\text { Relacionar os transtornos } \\
\text { mentais comuns em } \\
\text { agricultores com o uso de } \\
\text { agrotóxicos, sintomas } \\
\text { físicos, psíquicos e } \\
\text { doenças preexistentes. }\end{array}$ \\
\hline $\begin{array}{l}\text { A10 - Riscos à saúde } \\
\text { de trabalhadores } \\
\text { Rurais no } \\
\text { extrativismo da } \\
\text { Palha de carnaúba. }\end{array}$ & $\begin{array}{c}\text { Neto e } \\
\text { Crispim. / } \\
\text { Enferm Foco } \\
\text { [Internet]. } \\
\text { /2019. }\end{array}$ & $\begin{array}{c}\text { Pesquisa } \\
\text { descritiva, do } \\
\text { tipo estudo de } \\
\text { caso. / Ceará, } \\
\text { Brasil. } \\
\end{array}$ & $\begin{array}{c}\text { bvs - } \\
\text { LILACS. }\end{array}$ & $\begin{array}{l}\text { Identificar os riscos à } \\
\text { saúde dos trabalhadores } \\
\text { rurais no extrativismo da } \\
\text { palha de carnaúba. }\end{array}$ \\
\hline $\begin{array}{l}\text { A11 - Green Tobacco } \\
\text { Sickness among Thai } \\
\text { Traditional Tobacco } \\
\text { Farmers, Thailand. }\end{array}$ & $\begin{array}{l}\text { Saleeon et al. } \\
\text { /International } \\
\frac{\text { Journal of }}{\text { Occupational }} \\
\frac{\text { and }}{\text { Environmental }} \\
\frac{\text { Medicine/ }}{2015 .}\end{array}$ & $\begin{array}{l}\text { Estudo } \\
\text { quantitativo. / } \\
\text { Tailândia. }\end{array}$ & $\begin{array}{c}\text { bvs - } \\
\text { MEDLINE. }\end{array}$ & $\begin{array}{l}\text { Investigar a prevalência } \\
\text { de doença da folha verde } \\
\text { do tabaco e fatores de } \\
\text { risco relacionados entre } \\
\text { os agricultores } \\
\text { tradicionais tailandeses } \\
\text { de tabaco na província de } \\
\text { Nan, norte da Tailândia } \\
\end{array}$ \\
\hline $\begin{array}{l}\text { A12 - Refletindo a } \\
\text { interface entre } \\
\text { trabalho rural e } \\
\text { saúde mental dos } \\
\text { trabalhadores da } \\
\text { citricultura. }\end{array}$ & $\begin{array}{l}\text { Santos e } \\
\text { Menta. / Cad. } \\
\text { Ter. Ocup. } \\
\text { UFSCar. / } \\
2016 .\end{array}$ & $\begin{array}{c}\text { Estudo } \\
\text { exploratório de } \\
\text { natureza } \\
\text { empírica com } \\
\text { abordagem } \\
\text { qualitativa. / } \\
\text { Sergipe, Brasil. }\end{array}$ & $\begin{array}{l}\text { bvs - } \\
\text { LILACS. }\end{array}$ & $\begin{array}{l}\text { Descrever a estrutura } \\
\text { agrária e as condições de } \\
\text { trabalho no cultivo da } \\
\text { laranja do município de } \\
\text { Lagarto-SE, refletindo a } \\
\text { relação do trabalho na } \\
\text { citricultura com a saúde } \\
\text { mental do trabalhador, } \\
\text { expresso por meio do } \\
\text { abuso de álcool. }\end{array}$ \\
\hline
\end{tabular}




\begin{tabular}{|c|c|c|c|c|}
\hline $\begin{array}{l}\text { A13 - Padrões de } \\
\text { saúde e segurança } \\
\text { no trabalho e } \\
\text { extrativismo: o caso } \\
\text { de comunidades } \\
\text { rurais da Amazônia } \\
\text { brasileira. }\end{array}$ & $\begin{array}{l}\text { Veiga et al. / } \\
\text { Saúde Soc. } \\
\text { São Paulo / } \\
\quad 2017 .\end{array}$ & $\begin{array}{l}\text { Estudo de caso } \\
\text { em } \\
\text { profundidade } \\
\text { com coleta de } \\
\text { dados } \\
\text { primários com } \\
\text { adoção de } \\
\text { métodos } \\
\text { mistos para } \\
\text { sua } \\
\text { sistematização. } \\
\text { / Pará, Brasil. } \\
\end{array}$ & $\begin{array}{c}\text { bvs - } \\
\text { LILACS. }\end{array}$ & $\begin{array}{l}\text { Verificar as condições de } \\
\text { Saúde e Segurança no } \\
\text { Trabalho (SST) na coleta } \\
\text { de sementes oleaginosas, } \\
\text { e a forma como os } \\
\text { coletores compreendem } \\
\text { seu próprio envolvimento } \\
\text { na atividade de coleta, ou } \\
\text { seja, qual sua percepção } \\
\text { acerca dos riscos nos } \\
\text { quais estão envolvidos. }\end{array}$ \\
\hline $\begin{array}{l}\text { A14 - Sociedade de } \\
\text { risco: o uso dos } \\
\text { agrotóxicos } \\
\text { implicações } \\
\text { saúde do trabalhador } \\
\text { rural. }\end{array}$ & $\begin{array}{c}\text { Viero et al. / } \\
\text { Esc Anna } \\
\text { Nery / } 2016 .\end{array}$ & $\begin{array}{l}\text { Estudo do tipo } \\
\text { descritivo, com } \\
\text { abordagem } \\
\text { qualitativa. / } \\
\text { Rio Grande do } \\
\text { Sul, Brasil. }\end{array}$ & $\begin{array}{c}\text { bvs - } \\
\text { LILACS. }\end{array}$ & $\begin{array}{l}\text { Conhecer as percepções } \\
\text { de trabalhadores rurais } \\
\text { sobre os riscos advindos } \\
\text { do uso de agrotóxicos } \\
\text { para sua saúde. }\end{array}$ \\
\hline $\begin{array}{lr}\text { A15- } & \text { Workplace } \\
\text { Accident } & \text { Prevalence } \\
\text { and } & \text { Associated } \\
\text { Factors } & \\
\text { among } & \text { Tobacco } \\
\text { Farm in São } \\
\text { Lourenço do Sul-RS, } \\
\text { Brazil. }\end{array}$ & $\begin{array}{l}\text { Zago et al. / } \\
\text { Ciência \& } \\
\text { Saúde } \\
\text { Coletiva / } \\
2018 .\end{array}$ & $\begin{array}{l}\text { Estudo } \\
\text { transversal. / } \\
\text { Rio Grande do } \\
\text { Sul, Brasil. }\end{array}$ & $\begin{array}{c}\text { bvs - } \\
\text { MEDLINE. }\end{array}$ & $\begin{array}{l}\text { Avaliar a prevalência e os } \\
\text { fatores associados aos } \\
\text { acidentes de trabalho em } \\
\text { fumicultores em São } \\
\text { Lourenço Sul-RS. }\end{array}$ \\
\hline
\end{tabular}

Fonte: Elaborado pelo próprio autor com base na literatura científica selecionada para revisão (2020).

\section{RESULTADOS E DISCUSSÃO}

Dos quinze artigos selecionados, onze foram publicados nos últimos cinco anos (2015-2020), sendo dez da base de dados LILACS e cinco da MEDLINE; nove no idioma português e seis no inglês. Com exceção de uma pesquisa que não apresentou o local de realização (A4), os estudos foram realizados no Brasil (Acre, Ceará, Mato Grosso, Pará, Rio Grande do Sul e Sergipe), Coréia do Sul, Estados Unidos da América, Índia e Tailândia.

Após a leitura minuciosa dos artigos, emergiram-se cinco categorias temáticas (Quadro 2). Sendo elas: Riscos à saúde decorrentes do uso e exposição aos agrotóxicos, implicações à saúde decorrentes da fumicultura, implicações na saúde mental decorrentes do trabalho rural, riscos à saúde decorrentes da atividade 
extrativista e adoecimento do agricultor decorrentes a diferentes exposições no trabalho rural.

Quadro 2 - Categorias identificadas na revisão e seus respectivos artigos (ID):

\begin{tabular}{|l|c|}
\hline \multicolumn{1}{|c|}{ Categorias } & $\begin{array}{c}\text { Identificação dos } \\
\text { estudos }\end{array}$ \\
\hline $\begin{array}{l}\text { Riscos à saúde decorrentes do uso e exposição aos } \\
\text { agrotóxicos. }\end{array}$ & $\mathrm{A} 1 ; \mathrm{A} 6 ; \mathrm{A} 14$. \\
\hline $\begin{array}{l}\text { Implicações à saúde decorrentes da fumicultura. } \\
\mathrm{A} 3 ; \mathrm{A} 11 ; \mathrm{A} 15 .\end{array}$ & $\mathrm{A} 4 ; \mathrm{A} ; \mathrm{A} 12$. \\
\hline $\begin{array}{l}\text { Implicações na saúde mental decorrentes do trabalho rural. } \\
\text { Riscos à saúde decorrentes da atividade extrativista. }\end{array}$ & $\mathrm{A} 13$. \\
\hline $\begin{array}{l}\text { Adoecimento do agricultor decorrentes a diferentes } \\
\text { exposições no trabalho rural (Câncer de pele, Lesões na } \\
\text { córnea, Distúrbios Osteomusculares Relacionados ao } \\
\text { Trabalho e Doenças Relacionadas com o Calor). }\end{array}$ & $\mathrm{A}$. \\
\hline
\end{tabular}

Fonte: Elaborado pelo próprio autor com base na literatura científica selecionada para revisão (2020).

\section{Riscos à saúde decorrentes do uso e exposição aos agrotóxicos:}

O Brasil é um dos países que mais consome agrotóxicos no mundo, fator que coloca em risco não somente a saúde dos trabalhadores rurais, mas também a população residente em regiões próximas e expostas a utilização dos produtos. A dispersão de agrotóxicos entre áreas rurais e urbanas pode ocorrer devido a diversos fatores, tais como pelos aviões pulverizadores que percorrem grandes extensões de terra e os fortes ventos que transportam esses agentes químicos (BELO et al., 2012).

Outra questão a se considerar, é que nos processos produtivos agrícolas, geralmente o núcleo familiar está envolvido (mãe, pai, filhos e outros parentes), tornando todos vulneráveis a exposição aos agrotóxicos e consequentemente trazendo riscos à saúde; outro fator é falta de condições mínimas de segurança na manipulação desses agentes químicos, bem como a falta de orientação aos trabalhadores rurais e fiscalização no uso dos produtos (GREGOLIS; PINTO; PERES, 2012). 
De acordo com Viero e colaboradores (2016), em seu estudo, parte dos agricultores utilizavam agrotóxicos em suas atividades laborais há mais de 30 anos, caracterizando uma exposição crônica. Os participantes tinham ciência sobre os riscos da contaminação, dos sintomas de intoxicação aguda e das consequências da não utilização de Equipamentos de Proteção Individual (EPIs). No entanto, muitos negaram algum problema de saúde relacionado ao uso do agrotóxico e não consideravam essa exposição como um perigo à sua saúde. Outros, ainda que conheciam os riscos, não utilizam os EPIs corretamente.

Outros fatores de risco à saúde são o uso errôneo de agrotóxicos por agricultores familiares, como constatado no estudo de Gregolis, Pinto e Peres (2012), em que pequenos produtores rurais utilizavam entre os diversos agrotóxicos um inseticida à base de paration metílico denominado Folidol $\Theta$, além do Tamaron ${ }^{\circledR}$, de uso proibido no país. Além disso, grande parte deles não utilizava EPI, e entre os que o utilizavam eram equipamentos inapropriados, como por exemplo, calça e blusa de manga comprida como proteção.

Em um estudo realizado no Mato Grosso, com o objetivo de identificar os principais riscos ambientais e ocupacionais associados ao uso de agrotóxicos na produção de soja evidenciou um consumo elevado, também detectaram a presença de resíduos de agrotóxicos na água da chuva e pela análise de indicadores biológicos (amostras de sangue e urina) constatou-se a exposição ambiental a essas substâncias entre os trabalhadores rurais e população residente próxima a região de plantio, concluindo que é necessário o monitoramento ambiental e de saúde nas zonas produtoras de soja e que os riscos à saúde alcançam tanto os residentes em áreas rurais como urbanas (BELO et al., 2012).

Entre os motivos relatados por agricultores familiares para a não utilização de EPIs na pulverização com agrotóxicos, estão: o fato de não precisarem, de não possuírem os equipamentos, por não se preocuparem, porque atrapalha e por falta de orientação (GREGOLIS; PINTO; PERES, 2012). Outros apontam que a segurança contra a contaminação está no trator cabinado, ficando expostos a contaminações que os EPIs poderiam minimizar (VIERO et al., 2016). 


\section{Implicações à saúde decorrentes da fumicultura:}

O Brasil está entre os maiores produtores e exportadores de tabaco do mundo (FIORI et al., 2016). O cultivo de tabaco envolve mais de 200.000 famílias em atividades principalmente manuais, no Brasil é feito por agricultores familiares com pouca mecanização, o que exige uma força de trabalho maior e consequentemente, maiores chances de ocorrer acidentes de trabalho (ZAGO et al., 2018). Ressalta-se também, que de forma predominante, o cultivo do tabaco é realizado por pessoas do núcleo familiar (FIORI et al., 2016), potencializando a exposição e riscos à saúde a todos os membros da família envolvidos no trabalho.

Um dos principais riscos à saúde do agricultor no cultivo do tabaco é a Doença da Folha Verde do Tabaco (DFVT), comum em fumicultores. É uma patologia causada pela absorção da nicotina e têm como sintomas característicos a cefaleia, náusea, vômito e tontura (SALEEON et al., 2015).

Outro fator relevante é o risco aumentado do fumicultor se tornar tabagista. Um estudo realizado no Rio Grande do Sul identificou que a relação de trabalho no cultivo do tabaco é um fator de risco para o tabagismo, outros fatores associados foram o tempo de exposição a agrotóxicos (pesticidas) e o consumo excessivo de álcool (FIORI et al., 2016). Resultados semelhantes foram encontrados no estudo de Zago e colaboradores (2018) em que o consumo de álcool de alto risco foi referido por $26,7 \%$ e o tabagismo por $21 \%$ dos produtores de tabaco, além do envenenamento por pesticidas ao longo da vida, que foi relatado por $9,6 \%$ dos entrevistados.

Quanto aos acidentes de trabalho no cultivo do tabaco, em um estudo realizado no Rio Grande do Sul, identificou que 24\% tiveram lesões decorrentes de acidentes de trabalho e os principais fatores associados foi ser homem, ser arrendatário (pode estar relacionado a condições de trabalho mais precárias e estar sob maior pressão para realizar trabalhos), trabalho com o empacotamento das folhas de tabaco (manoca) e transtornos mentais como depressão e ansiedade 
(provavelmente pela menor capacidade de concentração nas tarefas) (ZAGO et al., 2018).

Os trabalhadores envolvidos no cultivo do tabaco estão expostos a vários riscos ocupacionais, por esta razão a relevância social e científica na abordagem desta temática, no intuito de promover a sensibilização dos fumicultores quanto aos riscos à saúde que estre trabalho representa e a implementação de estratégias de prevenção, por exemplo, no incentivo e orientação quanto ao uso de EPIs para minimização dos agravos (CARGNIN et al., 2016).

Implicações na saúde mental decorrentes do trabalho rural:

A saúde do trabalhador é uma área de interesse para profissionais de diferentes atuações, porém, ainda há uma escassez de estudos voltados para a saúde mental do agricultor (SANTOS; MENTA, 2016). A respeito da saúde de trabalhadores rurais, frequentemente os estudos científicos tratam sobre a saúde física, poucos priorizam a saúde mental ou a relação dos riscos ocupacionais e o sofrimento psíquico, sendo que esta área também é afetada (GIONGO; MONTEIRO; SOBROSA, 2017).

Assim como evidenciado nos estudos de Morim e Stumm (2018) realizado no Rio Grande do Sul, constatou-se que (47,9\%) dos agricultores possuíam Transtorno Mental Comum (TMC), sintomas físicos, emocionais e comorbidades (câncer, depressão, gastrite, doença cardíaca e hipertensão), associados a fatores como tempo na agricultura, exposição a agrotóxicos e outros TMCs preexistentes.

A precarização do trabalho rural também pode trazer sérias consequências a saúde mental, como constatado em um estudo com suinocultores, em que os trabalhadores tinham contato direto com os suínos e seus dejetos, em um ambiente úmido, empoeirado e com odor fétido, a limpeza do ambiente é realizada manualmente e mesmo com os riscos biológicos, os trabalhadores não utilizavam EPIs, além de se dividirem entre outras tarefas como necessidade de complementar 
a renda; aumentando a exposição a riscos físicos e mentais (GIONGO; MONTEIRO; SOBROSA, 2017).

Em um estudo realizado com trabalhadores da citricultura no Sergipe, com objetivo de refletir sobre as relações de trabalho e a saúde mental, foi evidenciado que a precariedade, exposições a altos riscos e desgastes no trabalho, são fatores que podem gerar transtornos psíquicos e o aumento no uso e abuso de álcool. (SANTOS; MENTA, 2016). A exposição a produtos químicos utilizados no trabalho agrícola, como os agrotóxicos, também é um fator de risco para saúde mental dos agricultores, muitas vezes os efeitos são tardios e irreversíveis (MORIM; STUMM, 2018).

Outro fator de risco para o sofrimento psíquico em trabalhadores rurais é a falta de reconhecimento social, por exemplo, quando o trabalho é visto apenas como manual e sem complexidade ou quando ao final de um ciclo produtivo os resultados são ruins e todo o trabalho deixa de ser valorizado por este fato (GIONGO; MONTEIRO; SOBROSA, 2017).

O desgaste devido a jornadas de trabalho "pesadas" e "intensas" também trazem consequências a saúde mental de trabalhadores rurais, principalmente devido ao comprometimento da vida social e familiar, aumentando o isolamento e diminuindo as redes de apoio, como evidenciado nas vivências de suinocultores (GIONGO; MONTEIRO; SOBROSA, 2017).

Como é comum no meio rural o trabalho ser realizado pelos membros da família, inclusive o trabalho infantil, os riscos à saúde física e mental podem se estender para a esposa, filhos e outros parentes (GIONGO; MONTEIRO; SOBROSA, 2017). As evidências reforçam a importância do aprofundamento e no desenvolvimento de pesquisas nesta temática, abordando todo contexto familiar.

\section{Riscos à saúde decorrentes da atividade extrativista:}

O trabalho na atividade extrativista ocorre de diferentes formas devido à variedade de recursos naturais, no entanto, a atenção à saúde e segurança do 
trabalhador rural na atividade extrativista, ainda é pouco explorada por meio das pesquisas científicas, provavelmente devido ausência de regulamentação pública e/ou pouca demanda por parte dos trabalhadores (VEIGA et al., 2017).

Durante a atividade extrativista, os trabalhadores rurais ficam expostos a diferentes riscos, por exemplo, na coleta da palha de carnaúba, os principais riscos são: físicos (luz solar, calor e ruídos), químicos (poeira do pó da palha), biológicos (fungos, vetores de doenças, animais peçonhentos), ergonômicos e organizativos (esforço físico intenso, postura inadequada, queda da palha sobre o próprio corpo, entre outros) (NETO; CRISPIM, 2019).

Já na atividade de coleta e armazenamento de sementes e frutos oleaginosos na Amazônia, que pode ocorrer em áreas de praias ou florestas, entre os riscos à saúde e segurança no trabalho estão, na praia: acidentes com arraias (no raso), com perfurocortantes (restos de vidro e metal), material contaminado (prego enferrujado), entre outros. Já na floresta: picadas de animais peçonhentos (cobra, escorpião, aranha), acidentes com espinhos de diferentes espécies vegetais, entre outros (VEIGA et al., 2017).

Os riscos à saúde deixam os trabalhadores rurais vulneráveis a sofrerem acidentes, agravos e doenças, por exemplo, a luz solar e o calor intenso podem causar câncer de pele, insolação e desidratação; vetores, podem transmitir doenças; já os riscos ergonômicos possibilitam o aparecimento de Lesões por Esforço Repetitivo (LER) e Doenças Osteomusculares Relacionadas ao Trabalho (DORT) (NETO; CRISPIM, 2019).

Um dos principais problemas encontrados na atividade extrativista é com relação a utilização de EPIs pelos trabalhadores. A conscientização sobre a importância do uso ainda é pouco disseminada e na maioria das vezes são os próprios trabalhadores que precisam adquirir os equipamentos, já outros deixam de usá-los, por hábito ou costume. Levando em consideração o aumento na demanda pelas indústrias processadoras de insumos naturais na Amazônia, os acidentes de trabalho e riscos à saúde e segurança do trabalhador tendem a aumentar (VEIGA et al., 2017). Diante disso, é necessário a elaboração e implementação de estratégias de promoção e prevenção a saúde do trabalhador rural na atividade extrativista, ressaltando a orientação sobre o uso adequado de EPIs (NETO; CRISPIM, 2019). 


\section{Adoecimento do agricultor decorrentes a diferentes exposições no trabalho rural (Câncer de pele, Lesões na córnea, Distúrbios Osteomusculares e Doenças relacionadas ao calor):}

Além dos riscos à saúde expostos nas categorias acima, o agricultor também está sujeito a outros agravantes, como o adoecimento em si. Dos artigos selecionados, quatro abordaram sobre doenças decorrentes do trabalho rural, mesmo se tratando de agravos diferentes, para melhor apresentação didática preferiu-se unir os estudos em uma só categoria.

Uma publicação abordou sobre o câncer de pele em trabalhadores rurais (CEZAR-VAZ et al., 2015), a segunda sobre lesões na córnea no trabalho da agricultura (GOEL et al., 2013), a terceira as doenças osteomusculares relacionadas ao trabalho agrícola (JO et al., 2016) e a última aborda as doenças relacionadas com o calor na atividade rural (LAM et al., 2013).

A exposição à radiação solar (risco físico) e aos agrotóxicos/pesticidas (risco químico), elevam as chances de o agricultor desenvolver câncer de pele (CEZARVAZ et al., 2015). Já a lesão na córnea, que pode levar a cegueira é um importante agravo que alguns trabalhadores agrícolas estão expostos, como constatado em uma pesquisa na índia com 584 pessoas envolvidas em atividades agrícolas. Em seus resultados, 221 pessoas sofreram lesões na córnea enquanto trabalhavam nos campos, quatro foram feridas mais de uma vez (GOEL et al., 2013).

Os Distúrbios Osteomusculares Relacionados ao Trabalho (DORT) também são um fator de adoecimento no trabalho agrícola. Conforme evidenciado em um estudo realizado com agricultores na província de Kangwon, Coréia do Sul, em que dos 1013 participantes, 925 relataram dor musculoesquelética em múltiplas áreas, sendo a dor lombar a mais frequente $(63,8 \%)$; o estudo também aponta que $53 \%$ dos participantes atuavam na agricultura há mais de 30 anos (JO et al., 2016).

As doenças relacionadas com o calor (DRC) também são uma causa importante de agravo que pode levar a morte de trabalhadores rurais. Em um estudo 
realizado em Washington, EUA, identificou que a maioria dos participantes nunca receberam treinamento formal com relação a DRC, porém, a maioria tinha consciência do que o calor extremo pode causar (desidratação, tontura...) (LAM et al., 2013).

\section{CONCLUSÃO}

Os agricultores estão expostos a diversos riscos à saúde decorrentes do trabalho rural, dependentes do contexto agrícola, no cultivo de espécies vegetais, no extrativismo e no cuidado com animais. Os riscos à saúde são abrangentes de acordo com a configuração de trabalho. As categorias evidenciam riscos decorrentes do uso e exposição aos agrotóxicos, no cultivo do tabaco, na atividade extrativista, implicações na saúde mental e agravos decorrentes de outras exposições no trabalho rural (câncer de pele, lesões na córnea, Distúrbios Osteomusculares Relacionados ao Trabalho (DORT) e Doenças Relacionadas com o Calor (DRC)).

Considerando a importância da atividade agrícola e os impactos na saúde em decorrência do trabalho rural, é necessário o desenvolvimento de mais pesquisas nesta temática e de trabalhos comparativos que sirvam como um diagnóstico situacional no campo das políticas públicas, considerando as regionalidades; no intuito de desenvolver estratégias para reduzir os danos ao agricultor decorrentes do trabalho rural. 


\section{REFERÊNCIAS BIBLIOGRÁFICAS}

BRASIL. Ministério da Saúde. Secretaria de Gestão Estratégica e Participativa. Departamento de Apoio à Gestão Participativa. Política Nacional de Saúde Integral das Populações do Campo e da Floresta. Brasília, 2013. 50 p.

BRASIL. Ministério da Agricultura, Pecuária e Abastecimento, Ministério da Fazenda, Banco Central do Brasil. Resolução no 4.174, de 27 de dezembro de 2012: Dispõe sobre a classificação de produtores rurais e sobre critérios para a apuração de saldos e para a fiscalização de financiamentos rurais. Brasília, 2013. 4 p.

BELO, M.S.S.P. et al. Uso de agrotóxicos na produção de soja do Estado do Mato Grosso: um estudo preliminar de riscos ocupacionais e ambientais. Rev. bras. Saúde ocup., São Paulo, v.37, n. 125, p. 78-88, jan./jun. 2012. DOI: http://dx.doi.org/10.1590/S0303-76572012000100011.

CARGNIN, M.C.S. et al. Fumante que não fuma: reflexão sob uma perspectiva ecológica. Cienc Cuid Saude, v. 15, n. 4, p. 762-767, out./dez. $2016 . \quad$ DOI: http://dx.doi.org/10.4025/cienccuidsaude.v15i4.27446.

CEZAR-VAZ, M.R. et al. Skin cancer in rural workers: nursing knowledge and intervention. Rev

Esc Enferm USP, São Paulo, v. 49, n. 4, p. 563-570, jul./ago. 2015. DOI: http://dx.doi.org/10.1590/S0080-623420150000400005.

DELGADO, G. C.; BERGAMASCO, S. M. P. P. (Org.). Agricultura familiar brasileira: desafios e perspectivas de futuro. Brasília: Secretaria Especial de Agricultura e do Desenvolvimento $\begin{array}{lllll}\text { Agrário, } 2017 . & 474 & \text { p. Disponível em: https://www.cfn.org.br/wp- }\end{array}$ content/uploads/2017/10/Agricultura_Familiar.pdf.

DEUS, R.M.; BAKONYI, S.M.C. O Impacto da Agricultura sobre o meio ambiente. REGET/UFSM Rev. Elet. em Gestão, Educação e Tecnologia Ambiental, Rio Grande do Sul, v. 7. n. 7, p. 1306-1315, mar./ago. 2012. Disponível em: http://cascavel.ufsm.br/revistas/ojs2.2.2/index.php/reget/index.

DIAS, E.C. Condições de vida, trabalho, saúde e doença dos trabalhadores rurais no Brasil. In: PINHEIRO, T.M.M. (Org.). Saúde do Trabalhador Rural - RENAST. p. 1-27, fev. 2006. Disponível em: http://www.luzimarteixeira.com.br/wp-content/uploads/2009/11/saudetrabalhador-rural.pdf.

FENZKE, M.N. et al. Adoecimentos e fatores relacionados à saúde do trabalhador rural. Rev enferm UFPE on line., Recife, v. 12, n. 8, p. 2214-2226, ago. 2018. DOI: https://doi.org/10.5205/1981-8963-v12i8a231532p2214-2226-2018.

FIORI, N.S. et al. Prevalência e fatores associados ao tabagismo em fumicultores do Sul do Brasil. Cad. Saúde Pública, Rio de Janeiro, v. 32, n. 7, p. 1-9, jul. 2016. DOI: http://dx.doi.org/10.1590/0102-311X00123115.

GIONGO, C. R.; MONTEIRO, J.K.; SOBROSA, G.M.R. Suinocultor: vivências de prazer e sofrimento no trabalho precário. Psicologia \& Sociedade, Belo Horizonte, v. 29, e147648, p. 1 11, mar. 2017, DOI: http://dx.doi.org/10.1590/1807-0310/2017v29147648.

GOEL, R. et al. Agriculture related corneal injuries. Nepal J Ophthalmol, v. 5, n. 9, p. 45-49, 2013. DOI: http://dx.doi.org/10.3126/nepjoph.v5i1.7821.

GREGOLIS, T.B.L.; PINTO, W.J; PERES, F. Percepção de riscos do uso de agrotóxicos por 
trabalhadores da agricultura familiar do município de Rio Branco, AC. Rev. bras. Saúde ocup., São Paulo, v. 37, n. 125, p. 99-113, jan./jun. 2012. DOI: https://doi.org/10.1590/S030376572012000100013.

JO, H. et al. Farmers' Cohort for Agricultural Work-Related Musculoskeletal Disorders (FARM) Study: Study Design, Methods, and Baseline Characteristics of Enrolled Subjects. J Epidemiol, v. 26 , n. 1, p. 50-56, 2016. DOI: 10.2188/jea.JE20140271.

LEITE, L.A.C et al. Vivência dos trabalhadores rurais frente ao Uso de agroquímicos: Uma revisão integrativa. Revista Interdisciplinar em Saúde, v. 8 (único), p. 379-390, 2021. DOI: DOI: 10.35621/23587490.v8. n1.p379-390.

LAM, M. et al. Identification of barriers to the prevention and treatment of heat-related illness in Latino farmworkers using activity-oriented, participatory rural appraisal focus group methods. BMC Public Health, v. 13, n.1004, p. 1-12, 2013. DOI: doi: 10.1186 / 1471-2458-13-1004.

LOPES, M.A.; CONTINI, E. Agricultura, Sustentabilidade e Tecnologia. Agroanalysis, Especial EMBRAPA, p. 27-34, fev. 2012. Disponível em: http://bibliotecadigital.fgv.br/ojs/index.php/agroanalysis/article/viewFile/24791/23560.

MENDES, K.D.S.; SILVEIRA, R.C.C.P.; GALVÃO, C.M. Revisão integrativa: Método de pesquisa para a incorporação de evidências na saúde e na enfermagem. Texto Contexto Enferm, Florianópolis, v. 17, n.4, p. 758-764, mar./out. 2008. DOI: http://dx.doi.org/10.1590/S010407072008000400018.

MORIM, P.V.; STUMM, E.M.F. Transtornos mentais comuns em agricultores, relação com agrotóxicos, sintomas físicos e doenças preexistentes. Psico (Porto Alegre), v. 49, n. 2, p. 196 205, 2018. DOI: http://dx.doi.org/10.15448/1980-8623.2018.2.26814.

NETO, F.R.G.X.; CRISPIM, F.S.P. Riscos à saúde de trabalhadores Rurais no extrativismo da Palha de carnaúba. Enferm Foco, v. 10, n. 2, p. 17-23, 2019. Disponível em: http://revista.cofen.gov.br/index.php/enfermagem/article/view/2281/513.

POSSAMAI, J. W.; BEZERRA, L. M. Aspectos legais de melhorias nas condições de trabalho na zona rural brasileira. Revista Científica Faculdade de Balsas, v. 9, n. 2, p. 58-71, 2018. Disponível em: https://www.unibalsas.edu.br/revista/index.php/unibalsas/article/view/68/62.

SALEEON, T. et al. Green Tobacco Sickness among Thai Traditional Tobacco Farmers, Thailand. Int J Occup Environ Med, v. 6, n 3, p. 169-176, july. 2015. DOI: 10.15171/ijoem.2015.540.

SANTOS, A.C.; MENTA, S.A. Refletindo a interface entre trabalho rural e saúde mental dos trabalhadores da citricultura. Cad. Ter. Ocup. UFSCar, São Carlos, v. 24, n. 4, p. 765-775, 2016. DOI: http://dx.doi.org/10.4322/0104-4931.ctoAO0718.

SILVA, J. A. Trabalhadores rurais na legislação trabalhista brasileira. 2014. Disponível em: https://joseandradedasilva.jusbrasil.com.br/artigos/124317872/trabalhadores-rurais-nalegislacao-trabalhista-brasileira.

VEIGA, J.P.C. et al. Padrões de saúde e segurança no trabalho e extrativismo: o caso de comunidades rurais da Amazônia brasileira. Saúde Soc., São Paulo, v.26, n.3, p.774-785, 2017. DOI: http://dx.doi.org/10.1590/s010412902017166075.

VIERO, C.M et al. Sociedade de risco: o uso dos agrotóxicos e implicações na saúde do trabalhador rural. Esc Anna Nery, Rio de Janeiro, v. 20, n. 1, p. 99-105, jan./mar. 2016. DOI: https://doi.org/10.5935/1414-8145.20160014.

VOSGERAU, D. S. R.; ROMANOVSKI, J. P. Estudos de revisão: implicações conceituais e 
metodológicas. Rev. Diálogo Educ., Curitiba, v. 14, n. 41, p. 165-189, jan./abr. 2014. DOI: 10.7213/dialogo.educ.14.041. DS08.

ZAGO, A.M. et al. Workplace Accident Prevalence and Associated Factors among Tobacco Farm in São Lourenço do Sul-RS, Brazil. Ciência \& Saúde Coletiva, Rio de Janeiro, v. 23, n. 5, p.1353-1362, mai. 2018. DOI: https://doi.org/10.1590/1413-81232018235.13172016. 